\title{
Structure and Distribution of an Alu-type Deletion Mutation in Sandhoff Disease
}

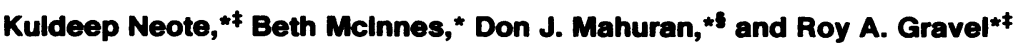

${ }^{*}$ Research Institute, Hospital for Sick Children, Toronto, Ontario M5G 1 X8, Canada ${ }^{\ddagger}$ Department of Medical Genetics, University of Toronto, Toronto, Ontario M5G 1A8, Canada; and ${ }^{\S}$ Department of Clinical Biochemistry,

University of Toronto, Toronto, Ontario M5G $1 \mathrm{LS}$, Canada

\begin{abstract}
Sandhoff disease is a recessively inherited lysosomal storage disease resulting from a deficiency of $\beta$-hexosaminidase activity. The enzyme occurs in two major forms, $\beta$-hexosaminidase $A$, composed of an $\alpha$ - and $\beta$-subunit and $\beta$-hexosaminidase $B$, composed of two $\beta$-subunits. Both isozyme activities are deficient in Sandhoff disease, owing to mutations of the $\mathrm{HEXB}$ gene encoding the common $\beta$-subunit. We have cloned and fully characterized a deletion at the $H E X B$ gene from fibroblasts of a patient with the infantile form of Sandhoff disease. The deletion removes $\sim 16 \mathrm{~kb}$ of DNA including the $\mathrm{HEXB}$ promoter, exons 1-5 and part of intron 5. It most likely arose from recombination between two Alu sequences, with the breakpoints occurring at the midpoint between the left and right arms in each case and regenerating an intact Alu element in the deletion sequence. The deletion allele accounts for $\mathbf{2 7 \%}$ of the Sandhoff mutant alleles we analyzed. Two cell lines were shown to be homozygous for the deletion and both had the infantile form of the disease. Four additional patients were compound heterozygotes with other mutations, all of whom displayed a different clinical phenotype. Finally, the mutant allele was present in different ethnic backgrounds, suggesting that it may have been subject to genetic drift. (J. Clin. Invest. 1990. 86:1524-1531.) Key words: $\mathbf{G M}_{2}$ gangliosidosis • lysosomal $\cdot$ polymerase chain reaction
\end{abstract}

\section{Introduction}

The $\mathrm{G}_{\mathrm{M} 2}$ gangliosidoses are a group of inherited disorders resulting from excessive accumulation of the ganglioside $G_{M 2}$ and related glycolipids in neuronal lysosomes of the brain and peripheral nervous system (1). The disease is caused by mutations in either of two proteins: the lysosomal $\beta$-hexosaminidase, which cleaves the terminal hexosamine from $\mathrm{G}_{\mathrm{M} 2}$ ganglioside; or a $G_{M 2}$ activator protein, which complexes with the lipid substrate and presents it to the enzyme for cleavage.

Lysosomal $\beta$-hexosaminidase consists of two major isozymes, hexosaminidase A $(\operatorname{Hex} A)^{1}$ and hexosaminidase B

Dr. Gravel's present address is McGill University, Montreal Children's Hospital Research Institute, 2300 Tupper St., Montreal, PQ, H3H 1P3 Canada. Please address reprint requests to him.

Received for publication 25 January 1990 and in revised form 21 May 1990.

1. Abbreviations used in this paper: Hex A, hexosaminidase A; Hex B, hexosaminidase B; PCR, polymerase chain reaction.

J. Clin. Invest.

(C) The American Society for Clinical Investigation, Inc.

0021-9738/90/11/1524/08 $\$ 2.00$

Volume 86, November 1990, 1524-1531
(Hex B). Hex A is composed of an $\alpha$ - and $\beta$-subunit, whereas Hex $B$ is composed of two $\beta$-subunits (reviewed in reference 2). Hex $A$ is the only isozyme that uses $G_{M 2}$ ganglioside as a substrate, although both isozymes can hydrolyse other glycolipids and artificial substrates (3). This difference in substrate specificity is attributed to unique substrate binding sites in $\alpha$ and $\beta$-subunits (4). The $\alpha$-subunit is encoded by the HEXA gene on chromosome 15 and the $\beta$-subunit is encoded by the $H E X B$ gene on chromosome $5(5)$. The $\mathrm{G}_{\mathrm{M} 2}$ activator gene has been localized to chromosome 5 (6). Mutations of these genes result in the three variant forms of $\mathrm{G}_{\mathrm{M} 2}$ gangliosidosis: TaySachs disease (variant B) is due to a defective $\alpha$-subunit, resulting in deficiency of Hex A activity (7); Sandhoff disease (variant $O$ ) is due to a defective $\beta$-subunit, resulting in a deficiency of Hex $A$ and Hex $B$ activity (8); and variant $A B$ is due to a defective $G_{M 2}$ activator protein (9).

Patients with $\mathrm{G}_{\mathrm{M} 2}$ gangliosidosis show a wide range of clinical severity and are further classified as infantile, late infantile, juvenile, and adult cases depending on the age of onset and severity of the disease. Although there is no sharp distinction between these subtypes, the broad group does relate to the severity of the biochemical lesion. For example, we have previously shown that the juvenile-onset form of Sandhoff disease can be biochemically differentiated from the infantile-onset form by the amount of residual Hex A activity in established fibroblast cell lines (10). Further, there have been three reports describing an adult-onset form of the disease (11-14). The disorder in these patients was limited to a motor neuron disease, presumably owing to only a partial deficiency of $\beta$-hexosaminidase. Finally, there is one case reported in which a normal individual with no apparent symptoms has a complete Hex A and Hex B deficiency when assayed with the artificial substrate but a carrier-like activity when assayed with the natural substrate (15).

Unlike Tay-Sachs disease, which has a high carrier frequency in the Ashkenazi Jewish population, no predominant ethnic group has been shown with a high Sandhoff disease carrier frequency (1). However, there are several geographic or demographic isolates with a high incidence of the disease. For example, there is an inbred community of Metis (North American Indians) in Northern Saskatchewan in which three cases of the disease have been described (16). 7 cases have been described in Lebanon (17) and an astonishing 36 cases in 15 families (over a 3-yr period) have been described in the Creole population of Argentina (18).

A thorough investigation of mutations in Sandhoff disease is important for two major reasons. First, it would allow the introduction of DNA-based diagnosis of specific mutations in the disease. Secondly, the mutations would provide clues about the functional domains of $\beta$-hexosaminidase that are important for lysosomal targeting and enzymatic activity. Little progress has been made in identifying mutations at the $H E X B$ gene. Thus far, only one mutation has been deter- 
mined: a point mutation in intron 12 in a patient with the juvenile form of Sandhoff disease (19). We had previously identified a partial $H E X B$ gene deletion in an individual with the infantile form of Sandhoff disease. We now show that the deletion appears to have resulted from an Alu-Alu recombination and that the mutant allele is prevalent in diverse populations expressing this disease.

\section{Methods}

The fibroblast cell lines GM317 and GM294 were obtained from the Human Genetic Mutant Cell Line Repository (Camden, NJ). The cell lines were maintained and propagated in $\alpha$-MEM media supplemented with $10 \%$ FCS. Genomic DNA from cells was isolated as described previously (20). Commercial materials were obtained from the following suppliers: Bethesda Research Laboratories (Gaithersburg, MD), Boehringer-Mannheim Biochemicals (Indianapolis, IN), International Biotechnologies Inc. (New Haven, CT), Pharmacia LKB Biotechnologies Inc. (Gaithersburg, MD), New England Biolabs (Beverly, MA), and United States Biochemical Corp. (Cleveland, OH). Radioisotopes were obtained from Dupont Co. (Wilmington, DE), or Amersham Corp. (Arlington Heights, IL).

Southern analysis. Genomic DNA digested with various restriction enzymes was separated by electrophoresis on a $0.6 \%$ agarose gel and transferred to Hybond-N (Amersham Corp.) as recommended by the supplier. The blots were hybridized using the Church and Gilbert method (21). Genomic probes were labelled using the random primer labeling kit from Boehringer-Mannheim as recommended.

Construction of genomic library. A genomic library was constructed in $\lambda \mathrm{gtWES}$ (Bethesda Research Laboratories). Briefly, genomic DNA $(\sim 30 \mu \mathrm{g})$ was digested with EcoRI and separated by electrophoresis on a $0.6 \%$ agarose gel. DNA between 12 and $15 \mathrm{~kb}$ was isolated by electroelution and further purified on a NACS column (Bethesda). After ethanol precipitation, DNA was ligated to equimolar amounts of lamda arms in a 10- $\mu$ l volume. Ligated DNA was packaged in vitro using Gigapak Gold (Stratagene Corp., La Jolla, CA) as recommended by the supplier and resulted in $\sim 5 \times 10^{6}$ recombinant clones. These were screened as described previously (22) with two genomic probes, EH1.1 and Pst 1.0 (see Results).

Analysis of recombinant clones. DNA from purified phage clones was isolated as described (23). The DNA was analyzed by various restriction enzymes and compared with normal genomic clones previously isolated (22). DNA fragments were subcloned into Bluescript vectors (Stratagene Corp.) and further mapped as described previously (22).

$D N A$ sequencing. Fragments to be sequenced were subcloned into either $\mathrm{pBS}(+)$ or $\mathrm{pBS}(-)$. Fragments not having clonable ends were made blunt by treatment with Klenow (Bethesda Research Laboratories) or T4 polymerase (Pharmacia) as described by Maniatis et al. (24). Single-stranded DNA was isolated and sequenced as described previously (22).

DNA amplification. The mutant alleles in Sandhoff cell lines were examined by the polymerase chain reaction (PCR) procedure. The deletion allele (see below) was amplified by PCR with primers flanking the deletion junctions (Fig. 5). The normal allele was detected using primers in exon 4 (5'-GAGACCTTTAGCCAGTTAGT) and exon 5 (5'-AGAATAATCTTAACTGGCAG). The amplifications were done in 50- $\mu$ l reactions containing $0.2-0.5 \mu \mathrm{g}$ of DNA, $10 \mathrm{mM}$ Tris- $\mathrm{HCl}$ (pH $8.3), 50 \mathrm{mM} \mathrm{KCl}, 1.5 \mathrm{mM} \mathrm{MgCl}, 1.5 \mathrm{mM}$ of each dNTPs, $0.01 \%$ gelatin, $1 \mu \mathrm{M}$ of each primer, and $2.5 \mathrm{U}$ of Taq polymerase (PerkinElmer Cetus Corp., Norwalk, CT). The reactions were run in a Cetus/ Perkin-Elmer DNA thermal cycler for 35 cycles, each consisting of denaturation at $94^{\circ} \mathrm{C}$ for $0.5 \mathrm{~min}$, annealing at 55 or $60^{\circ} \mathrm{C}$ (for normal and mutant reactions, respectively) for $0.5 \mathrm{~min}$ and extension at $72^{\circ} \mathrm{C}$ for $1.5 \mathrm{~min}$. The amplified products were analyzed on a $1.5 \%$ agarose gel.

\section{Results}

Southern blot analysis of genomic DNA from Sandhoff cell lines GM317 and GM294, using the $\beta$-subunit cDNA as probe, had previously revealed a partial $H E X B$ gene deletion at the $5^{\prime}$ end (10). To further localize these deletions, Southern blot analysis was carried out with various genomic probes subcloned from the $H E X B$ gene. Two probes were informative. One was EH1.1, a 1.1-kb Eco RI-Hinc II fragment $\sim 5 \mathrm{~kb}$ upstream of exon 1 (Fig. 1). It detected single DNA fragments after cleavage of genomic DNA with Eco RI, Bam HI, Hind III, Xba I, and Pst I (Fig. 2). Two DNA fragments are detected with Sst I, since the probe spans a Sst I site, a 5' 8-kb fragment and a $3^{\prime} 12-\mathrm{kb}$ fragment (Fig. $2 \mathrm{~B}$ ). Since the probe hybridizes to only $\sim 200 \mathrm{bp}$ of the $5^{\prime} 8-\mathrm{kb}$ band, as compared with $900 \mathrm{bp}$ of the $3^{\prime} 12-\mathrm{kb}$ band (see restriction map in Fig. 1), the 8-kb band is barely detectable (Fig. $2 B$ ). The second informative probe, Pst 1.0, spans exon 6 (Fig. 1) and has been previously described (25). It detects single $H E X B$ gene fragments (Fig. 3, arrows) as well as other DNA fragments unrelated to the $H E X B$ gene with some restriction enzymes (e.g. Fig. 3, lower bands in Bam HI and Hind III digests). When Southern blots were probed with EH1.1, abnormal restriction fragments were revealed in the DNA of both GM317 and GM294 fibroblasts after cleavage with Eco RI, Bam HI, Hind III, and Pst I, but not with Xba I (Fig. 2). An abnormal 4-kb fragment was also detected with Sst I; however, the 5' 8-kb fragment was unaltered (Fig. 2 B). When the same blots were probed with Pst 1.0, abnormal fragments were detected with Eco RI and Hind III (Fig. 3) as well as with Bam HI (see below), but not with the Sst I, Pst I, and Xba I (data not shown). Significantly, the abnormal Eco RI and Hind III fragments detected by both probes were of similar mobility (compare Fig. $2 A$ and 3 ), suggesting that the same fragments were being detected as a result of the deletions. The same appeared true of the Bam HI digests, except that here the apparent abnormal fragment detected by EH1.1, and consequently by Pst 1.0 as well, had a mobility similar to that of the normal fragment detected by Pst 1.0 (compare abnormal Bam HI fragments in Fig. $2 \mathrm{~A}$ with upper Bam HI fragments in Fig. 3). Finally, there was no hybridization of exon 4- or 5-specific probes to the mutant DNAs (data not shown). These data suggest the deletions in GM317 and GM294 were likely identical to each other and in the homozygous state.

These results localized the deletions to a region beginning $\sim 2 \mathrm{~kb}$ upstream of exon 1 (first Xba I site in Fig. 1) to a site $5^{\prime}$ of exon 6. To define the detailed structure of the deletion, the abnormal $13 \mathrm{~kb}$ Eco RI fragment of GM317 was cloned. A size selected genomic library was constructed in $\lambda \mathrm{gtWES}$ and screened with both the EH1.1 and Pst 1.0 probes. Three clones were isolated that hybridized with both probes. One of the clones was restriction mapped and revealed that the deletion junction is within a 1.0-kb Xba I-Xho I fragment (Fig. 1), since all restriction enzyme sites $5^{\prime}$ or $3^{\prime}$ to the deletion junction were found to be identical to corresponding sites upstream of exon 1 or downstream of exon 5 . The sites corresponding to the deletion end points in the normal clone were within a 0.3-kb Eco RI-Xba I fragment at the $5^{\prime}$ end and within a 1.6-kb SstI-XhoI fragment at the $3^{\prime}$ end (Fig. 1). The deletion in GM317 therefore removes $\sim 16 \mathrm{~kb}$ of DNA including $\sim 2$ $\mathrm{kb}$ of the $5^{\prime}$ flanking sequence that contains the $H E X B$ promoter, as well as exons $1-5$ and part of intron 5 . 


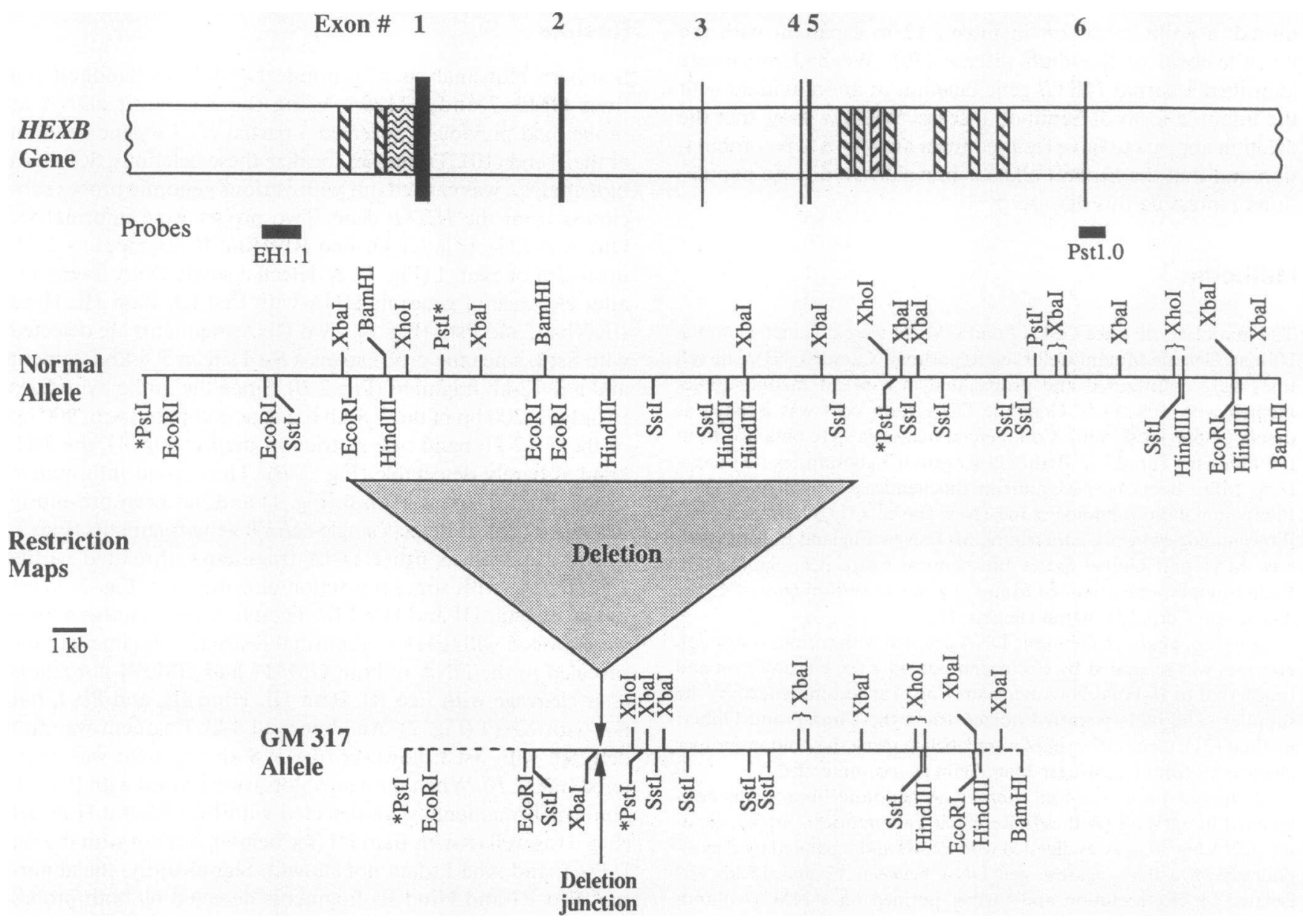

Figure 1. Restriction maps of the normal and the deletion-bearing (GM317) HEXB gene. The normal HEXB gene is depicted on the top as follows: $\square$, exons; $\square$, introns; , HEXB promoter; $\mathbb{Z}$, Alu $\left(5^{\prime}-3^{\prime}\right) ; \square$, Alu $\left(3^{\prime}-5^{\prime}\right)$. Restriction sites in the normal gene, shown below, were mapped on normal genomic clones encompassing the gene and are updated from those previously determined (22). Pst I sites, indicated by asterisks, relevant to the interpretation of Southern blots (Figs. 2 and 3) are shown, the two at the $5^{\prime}$ end were precisely mapped and the one at the $3^{\prime}$ end was deduced from the Southern analysis. Restriction sites in GM317 allele, shown at the bottom, were determined from the cloned Eco RI fragment bearing the deletion junction. Broken lines represent restriction sites extrapolated from the normal clone to help interpret the Southern blots. All restriction sites were determined as described in Methods. DNA sequences that are deleted together with the deletion junction are shown. Probes EH1.1 and Pst 1.0 used for Southern blot hybridization and library screening are indicated as black bars. Note that the presence of additional Alu sequences cannot be excluded since the normal gene depicted has not been sequenced in its entirety.

The deletion junction was further identified by obtaining a detailed restriction map (Fig. 4) and sequencing across the site of the deletion in mutant DNA $(2.0-\mathrm{kb}$ Xba I fragment of GM317) and the corresponding $5^{\prime}$ site (0.3-kb Eco RI-Xba I fragment) and $3^{\prime}$ site (1.6-kb Sst I-Xho I fragment) in normal DNA (Figs. 1 and 4). Comparison of the nucleotide sequence across the deletion and the corresponding junction sites in normal DNA revealed that the breakpoint occurred within a span of 29 nucleotides that are identical at the $5^{\prime}$ and $3^{\prime}$ sites in normal DNA (Fig. 5, uppercase). The DNA sequence of the deletion clone on either side of this region matches perfectly the $5^{\prime}$ and $3^{\prime}$ normal sequence, indicating that no insertion or addition of extraneous DNA sequences has occurred during the deletion event. Computer-assisted analysis of the sequences around the deletion junctions indicated that these sequences are homologous to the Alu repetitive element. Furthermore, the deletion event has resulted in a reconstituted Alu sequence, the left half of which is from the $5^{\prime}$ Alu sequence and the right half of which is from the $3^{\prime}$ Alu sequence (Fig. 5, solid bar over and underneath the sequence). Sequencing of other DNA fragments from intron 5 revealed the presence of additional Alu sequences that are schematically shown in Fig. 4.

We next used PCR to compare the deletions in GM317 and GM294 and to determine if the mutant allele was present in other Sandhoff cell lines. The normal allele was detected using primers contained within the deletion segment, one in exon 4 and other in exon 5 to give a PCR product of $385 \mathrm{bp}$ (see Methods). The deletion allele was amplified using primers flanking the deletion junction (Fig. 5). They yielded a PCR product of $506 \mathrm{bp}$ when the deletion was present but no product with normal DNA since the primers were $\sim 16 \mathrm{~kb}$ apart, although, in some experiments, an aberrant band of $\sim 800 \mathrm{bp}$ could be seen with normal DNA (Fig. $6 A$ ). When DNA from GM317 was used, only the 506-bp band was observed, confirming the presence of the deletion in the homozygous state (Fig. 6). DNA from GM294 behaved identically, giving the 506- but no 385-bp PCR product (Fig. 6). Analysis of the two 
A
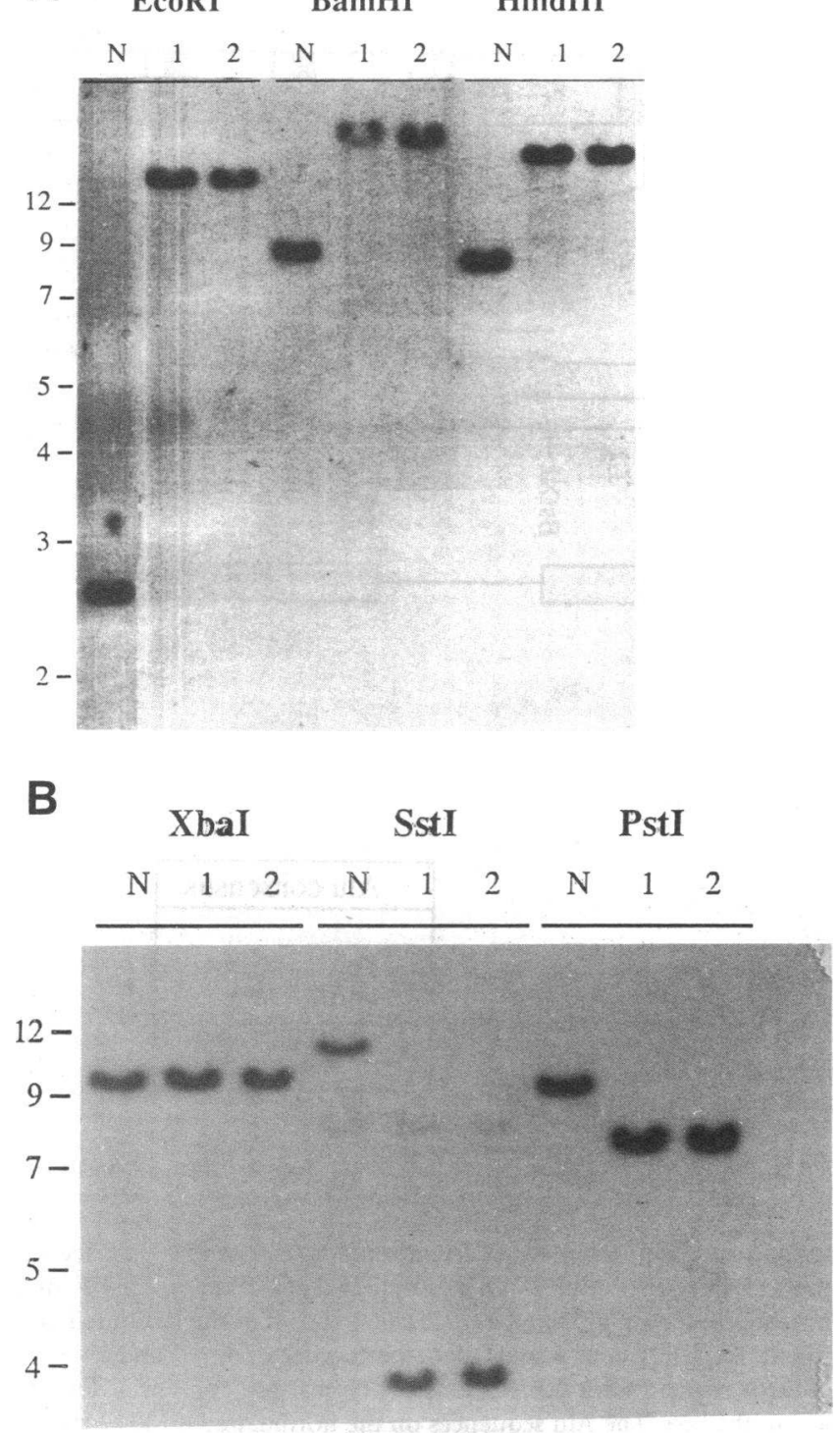

Figure 2. Southern blot hybridization of DNA from normal, GM317 and 294 fibroblasts. DNA $(10 \mu \mathrm{g})$ isolated from normal (lane $N)$, GM317 (lane 1) and GM294 (lane 2) cell lines were digested with the restriction enzymes indicated. The DNA was run on $0.6 \%$ agarose gel, transferred to Hybond-N membranes and hybridized with probe EH1.1. Size markers are indicated in kilobases.

PCR products by cleavage with several restriction enzymes also showed them to be identical (data not shown). We conclude, therefore that GM317 and GM294 carry the same mutant allele.

The occurrence of the deletion allele was next examined in 20 different Sandhoff cell lines that are clinically and ethnically diverse. The mutation was present in four additional cell lines, WG534, 2399, 2557, and GM 2094 (Fig. 6). All these cell lines proved to be compound heterozygous since both the 506and 385-bp fragments were detected in each case (Fig. 6). Our previous analysis of some of these cell lines by Southern blot hybridization using the cDNA as probe did not reveal the presence of the deletion allele. We surmise that it generated a large restriction fragment that was either undetectable or masked by the non-deleted allele. The results of the PCR anal-

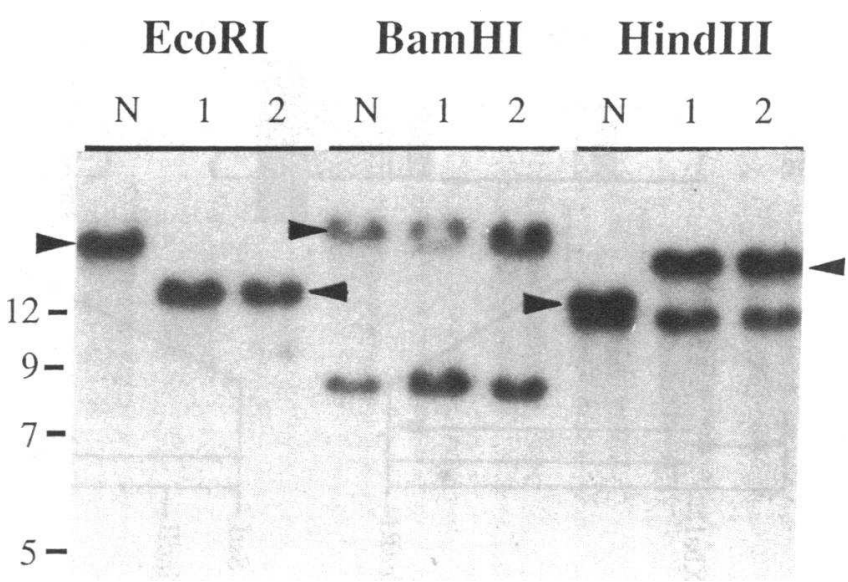

Figure 3. Southern blot hybridization of DNA from normal, GM317, and GM294. DNA $(10 \mu \mathrm{g})$ isolated from a normal (lane $N$ ), GM317 (lane 1), and GM294 (lane 2) cell lines were digested with the restriction enzymes indicated. Details are as shown in Fig. 2 except hybridization was with probe Pst 1.0. Arrows indicate restriction fragments from the $H E X B$ gene expected to hybridize to Pst 1.0. The lower bands in the Bam $\mathrm{HI}$ and Hind III lanes are restriction fragments that cross hybridize with Pst 1.0 but are unrelated to the $H E X B$ gene. Size markers are indicated in kilobases.

ysis for all the Sandhoff cell lines is shown in Table 1 . The mutation was observed in $8 / 30$ or $27 \%$ of mutant alleles in our collection of Sandhoff disease cell lines.

Finally, we have confirmed the presence of the intron 12 point mutation by allele-specific hybridization of PCR products in GM 2094 (data not shown) as reported by Nakano and Suzuki (19). This intron 12 mutation was not present in any of the other Sandhoff cell lines listed in Table I.

\section{Discussion}

In this study, we have identified the structure and distribution of a deletion mutation prevalent in Sandhoff disease. The deletion is $\sim 16 \mathrm{~kb}$ long and spans from $\sim 2 \mathrm{~kb}$ upstream of exon 1 to within the first $\sim 1.5 \mathrm{~kb}$ of intron 5 . Two individuals homozygous for the deletion had the severe, infantile form of Sandhoff disease and died by the age of 18 mo $(26,27)$. Cell lines from both patients had undetectable $H E X B$ mRNA (10) or hexosaminidase $\beta$-subunits (28), owing to the absence of the $H E X B$ promoter or 5 ' coding sequences (22).

It is clear from the sequence of the deletion junction and of the deletion end points in the normal gene that Alu sequences are involved. Alu sequences are moderately repetitive sequences present at $\sim 500,000$ copies in the haploid human genome (29). They consist of a $\sim 300$-bp sequence that originated from a duplication of a 150-bp sequence (29). The left half of the dimer differs from the right due to a 31-bp insertion and the Alu sequence is terminated by a poly A-like structure. The entire structure is flanked by direct repeats that vary in length from 7 to $25 \mathrm{bp}$. The deletion end points at the $5^{\prime}$ and $3^{\prime}$ ends are within Alu sequences, the orientation of which are opposite to that of the $H E X B$ gene. The sequence of the deletion junction shows that the right arm of an Alu sequence at the $5^{\prime}$ end is joined to the left arm of the Alu sequence at the $3^{\prime}$ end. The junction appears to have occurred within a region of 29 nucleotides that are identical between the $5^{\prime}$ and the $3^{\prime}$ Alu sequence. This region is at the boundary of the left and right 


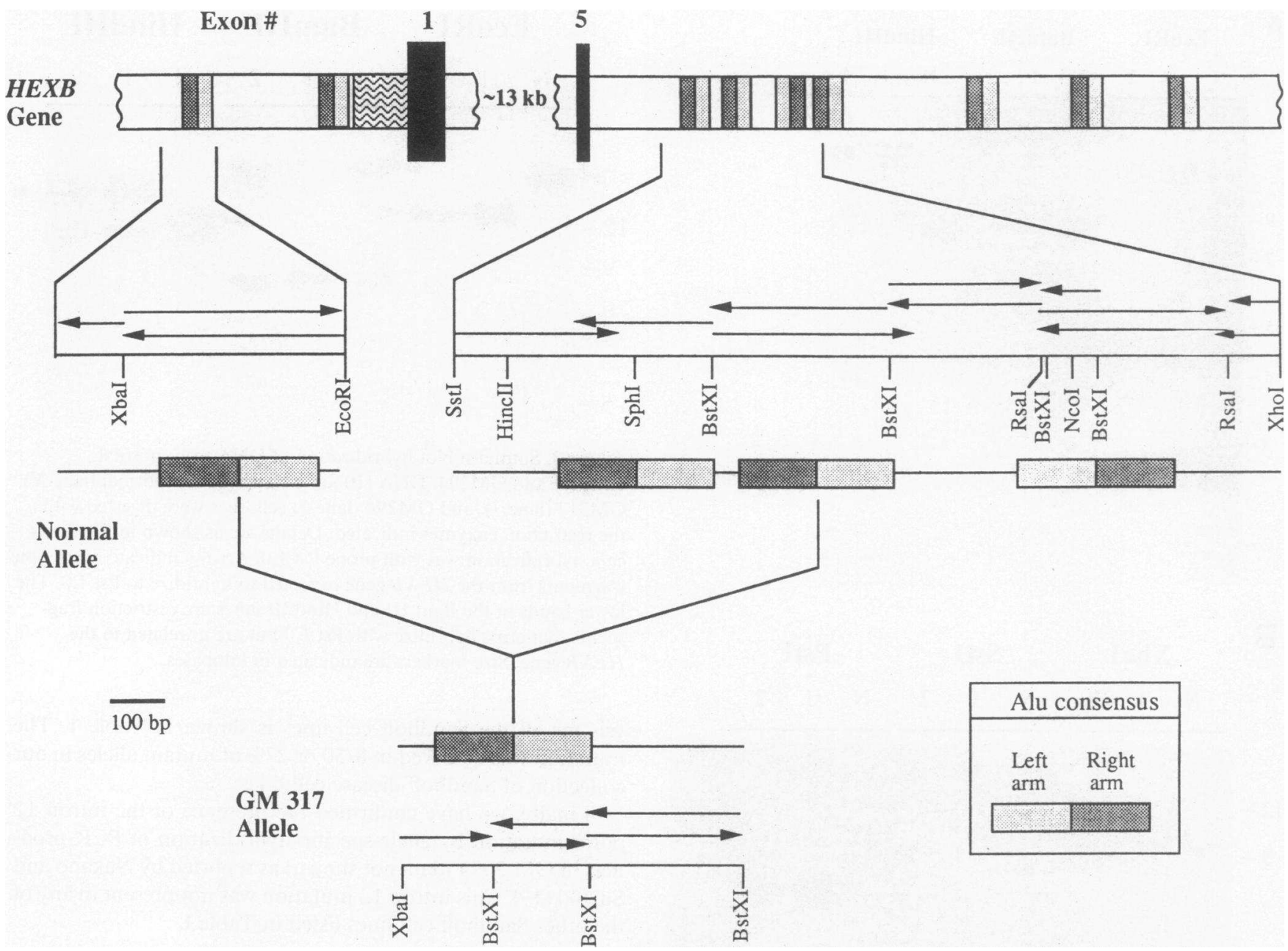

Figure 4. Detailed restriction maps and sequencing strategy of DNA fragments involved in the deletion. The normal $H E X B$ gene is depicted on the top as follows: $\square$, exons; $\square$, introns; $3^{\prime}$ fragments corresponding to the deletion boundaries are shown below. The restriction map of the GM317 allele is shown at the bottom. The arrows indicate the direction and extent of DNA sequenced from each fragment. Each fragment was subcloned into $\mathrm{pBS}(+)$ or $(-)$ and sequenced with either the T3 or T7 primer, using as templates single stranded DNA rescued from the subclones. A typical Alu consensus dimer as described by Schmid and Jelinek (29) with the left and right arms is shown in the box. The Alu sequences on the normal and GM317 alleles are schematically depicted above or below the restriction maps. The Alu repeats at the $5^{\prime}$ and $3^{\prime}$ end of the normal allele involved in the deletion together with the reconstituted Alu repeat in the GM317 allele are shown.

arm of the Alu sequence and leaves the resulting Alu sequence intact (Figs. 4 and 5). We surmise that the deletion mutation occurred by misalignment and recombination of homologous Alu sequences on the same or different chromatids during meiosis. This would result in the excision of the intervening sequence in one case or the deletion and duplication of alleles in the other case. The presence of additional deletions at the $H E X B$ locus has been shown by field inversion gel electrophoresis, although the exact size of the deletions have yet to be confirmed by detailed analysis (30).

A similar Alu-type deletion has been described at the HEXA gene in Tay-Sachs disease (31). Here exon 1 and $7 \mathrm{~kb}$ of flanking DNA were deleted due to an apparent Alu recombination. In this instance, the $5^{\prime}$ deletion boundary sequence corresponds not to an Alu repeat per se but to a sequence homologous to the left half of an Alu dimer. The exact deletion junction was shown to be $85 \mathrm{bp}$ upstream of this Alu-like sequence. Deletions involving Alu repeats seems to account for a large number of mutations in other genes, e.g., in the
LDL receptor genes $(32,33)$ the $\gamma, \delta, \beta$-globin gene complex $(34,35)$, and apolipoproteins B gene (36). One notable difference between the deletion we have described and other AluAlu deletions is that most other deletion junctions seem to be clustered in the left arm of the Alu sequence in a region implicated in transcription by RNA polymerase III (32).

The deletion allele is present at a surprisingly high frequency, $27 \%$ of the Sandhoff alleles we have examined. It was shown to be present in the homozygous state in two individuals and as part of a compound heterozygote in four others. Three of the latter individuals were of French or French-Canadian origin. It is possible that the mutation arose in the French population and was further distributed by a founder effect and genetic drift. Alternatively, the high prevalence of the allele could be the product of several independent mutational events as documented elsewhere for deletions involving Alu-repetitive elements (32). The latter argument seems unlikely here since restriction enzyme analysis of the amplified deletion allele from two ethnically diverse individuals has shown that 
5. normal

Deletion

3' normal

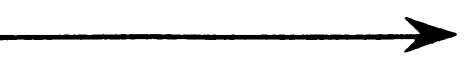

acctctttatggctggctcctacagaagacacggcaagattagagtaatatttctagatttatgactg acctcttatggctggctcctacagaagacacggcaagattagagtaatatttctagatttatgactg

tggattigcaggagagagica

5. normal getttgggggoatagxxxxxxxxxnnnnnnnnnnnnnnnnnnnnnnn

" normal gcttgggggcataggggctctagtttcttcttttttttttctttctgagacagagtcttactctgt

Deletion gcttgggggcataggggctctagttcttctttttttttttcttctgagacagagtcttactctgt

3' normal cogtgccoagccaaaattattattattattattattttttttctattt-agttgaagtcttgctctgt xxxxxxxxxxnnnnnnnnnnnnnnnnnnnnnnnnnnnn-

5' normal ggcacaggctggagtgcagtggtgcaatctcggctcactgcaactctgcctcccaggttcaagtgattc

Deletion ggcacaggctggagtgcagtggtgcaatctcggctcactgcaactctgct cciggttcaagtgattc

3' normal -cgccaggctggagggcagtggtgcaatct

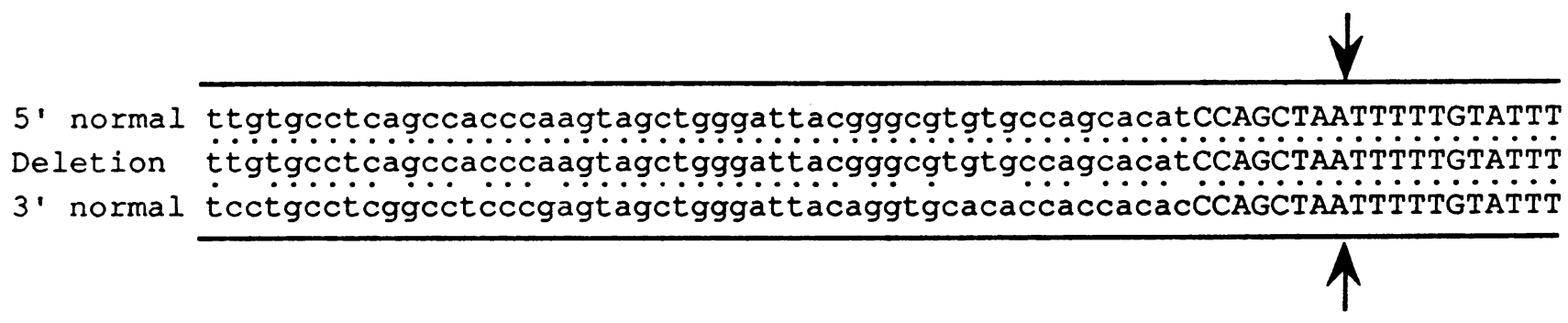

5' normal TTAGTAGAGAtgaggtttcaccatgttggccaggctggtctcgaactcctggccttaagtgatccacctg

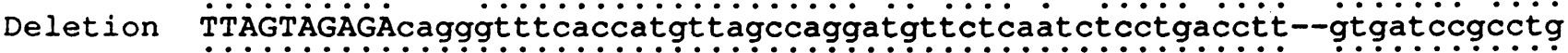

3' normal TTAGTÄÄGACagggtt $c a c c a t g t t a g c c a g g a t g t t c t c a a t c t c c t g a c c t--g t g a t c c g c c t g$

5' normal ccttggcctcccaagtgctgggattacaggcgtgagccaccatgccoacagtggctctagtttctgtg Deletion cotcagctco 3' normal cctcagcctcciagtgcatgggattacaggtgtgagccaccacgctggctaaaattattt icat $\operatorname{xxxx\times x\times x\times x}$

5' normal acccatttgaaaagaggaattc

Deletion ttacätaatactctgaatttttctccaaagacagtcttgtcactttaagaaacagatgcttagtgt 3 ' normal ttacattaatactctgaatttttctccaaagacagtcttgtcacttiaagaacagatgcttagtgt

Deletion aaagtttaacaatataatgtgcataaataggcagtcatcccatatttcatttgccaaga

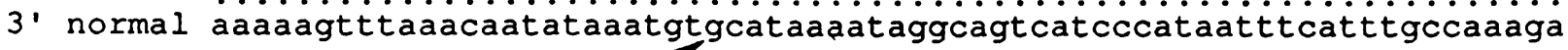

Figure 5. DNA sequence of the $5^{\prime}$ and $3^{\prime}$ normal allele corresponding to the deletion boundaries together with deletion junction in the GM317 allele. The designations $5^{\prime}$ normal, deletion, and $3^{\prime}$ normal are for $5^{\prime}$ flanking, the deletion junction, and intron 5 , respectively, of the normal or mutant alleles. Identical bases are indicated with dots. Gaps (-) were inserted to achieve maximum homology. The Alu sequences at the $5^{\prime}$ and $3^{\prime}$ normal allele are shown as solid bars above and below the sequences. The polyA-like structures at the end of the Alu sequences are indicated by $n$ above or below the sequence. The direct repeats at the ends of the Alu sequences are indicated by $x$ above or below the sequence. The sequence in capital letters shows the limits of the deletion junction. The vertical arrows indicate the junctions of the left and the right arm of the Alu sequences. Primers used for the PCR reactions are shown as horizontal arrows above or below the sequence together with their orientation. Note that the Alu sequences are in the opposite orientation of the $H E X B$ gene and therefore the complementary strand is depicted above. These sequence data are available from EMBL/GenBank/DDBJ under accession numbers M37468, M37469, and M37470. 


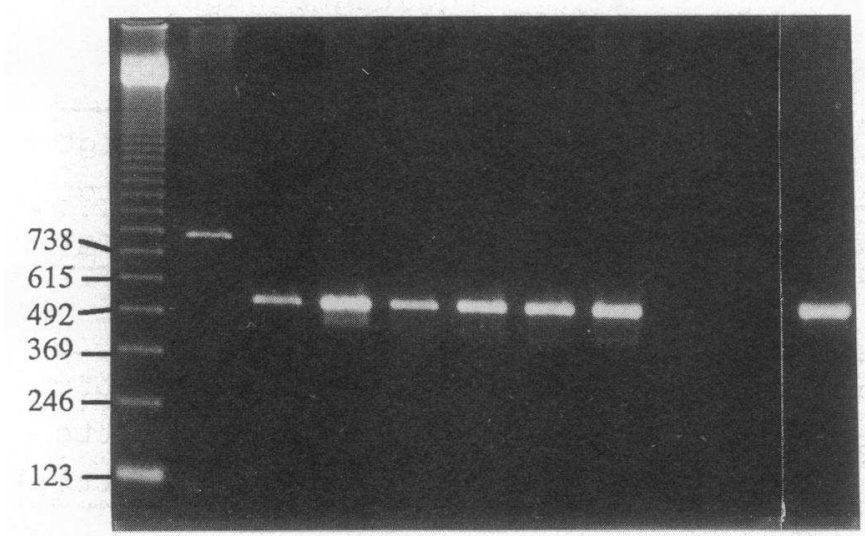

B
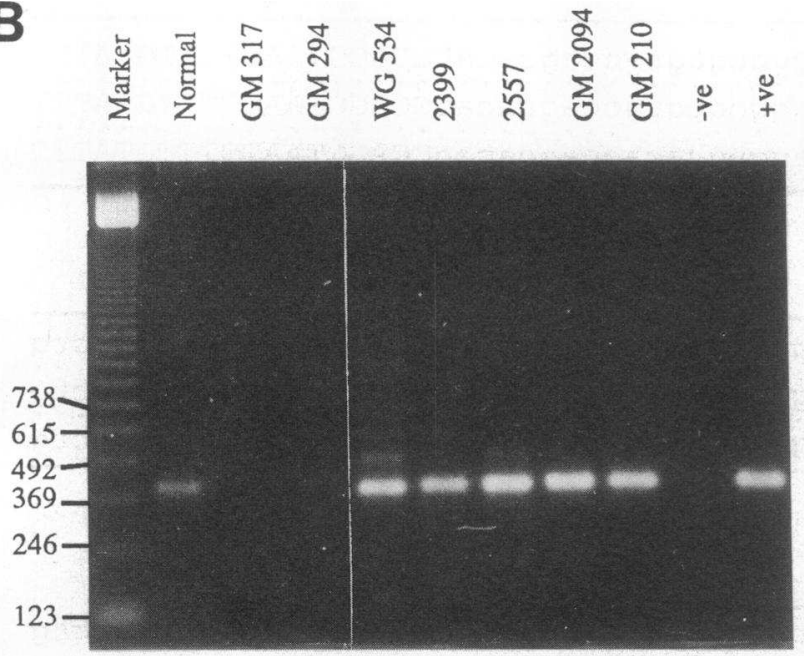

Figure 6. PCR analysis of Sandhoff fibroblast cell lines. Genomic DNA $(0.1-0.5 \mu \mathrm{g})$ was amplified with primers spanning the deletion junction $(A)$ or with primers within the deletion segment $(B)$ as described in Methods. Cell lines are identified with numbers at the top of each lane. Markers shown are the 123-bp ladder obtained from BRL. Cell lines GM317 and GM294 are homozygous for the deletion. Cell lines WG 534, 2399, 2557, and GM2094 are compound heterozygous containing one deletion allele and a different second mutant allele. GM210 is a typical example of a cell line that was found not to have the deletion allele. The +ve lane represents a PCR reaction using a cloned fragment encompassing the primers as the template and the $-v e$ lane represents a PCR reaction with no DNA.

they are most likely the same allele. A more detailed analysis, such as DNA sequencing of the amplified mutant allele, would be required to investigate these possibilities.

The four individuals with Sandhoff disease who are heterozygous for the deletion covered the spectrum of onset and severity of the disease. Since the deletion homozygotes have a typical infantile form of the disease, any amelioration of the clinical phenotype in those heterozygous for the deletion must be due to the expression of the second allele only. Thus, the intron 12 mutation described by Nakano and Suzuki (19) is responsible for the juvenile phenotype in that patient. This
Table I. Occurrence of Deletion Mutation in Sandhoff Disease Cell Lines

\begin{tabular}{|c|c|c|c|}
\hline Cell lines* & Ethnic group & $\begin{array}{l}\text { mRNA } \\
\text { levels** }\end{array}$ & Mutation(s) $)^{ \pm}$ \\
\hline \multicolumn{4}{|l|}{ Infantile } \\
\hline 2012 & Unknown & Normal & $? / ?$ \\
\hline 1146 & Laotian & Normal & $? / ?$ \\
\hline 2010 & Mexican & Normal & $? / ?$ \\
\hline 2007 & Mexican & $<10 \%$ & $? / ?$ \\
\hline 322 & Metis Indian & $<10 \%$ & ?/? \\
\hline WG 534 & French Canadian & $<10 \%$ & Del/? \\
\hline 1954 & Argentinian & $<10 \%$ & ?/? \\
\hline 2182 & Argentinian & ND & ?/? \\
\hline GM 470 & Mexican & $<1 \%$ & ND \\
\hline GM 203 & Caucasian/Indian & $<1 \%$ & ND \\
\hline GM 317 & U.S. Black & $<1 \%$ & Del/Del \\
\hline GM 294 & Caucasian & $<1 \%$ & Del/Del \\
\hline \multicolumn{4}{|l|}{ Juvenile } \\
\hline 1279 & British Caucasian & Normal & ND \\
\hline GM 2094 & Caucasian & Normal & Del/Intron 12 \\
\hline MGV 229 & Unknown & Normal & ND \\
\hline 1303 & East Indian & Normal & ?/? \\
\hline GM 210 & Lebanese & $<10 \%$ & $? / ?$ \\
\hline \multicolumn{4}{|l|}{ Adult } \\
\hline $2400^{8}$ & French Canadian ${ }^{\S}$ & Normal ${ }^{\S}$ & Del/? \\
\hline $2557^{\prime \prime}$ & French & $<10 \%$ & Del/? \\
\hline
\end{tabular}

* Source and information about the cell lines is taken from O'Dowd et al. (1986) or indicated.

* Tests were done for the deletion and intron 12 mutations (Nakano and Suzuki, 1989) (19). ?, presence of neither allele.

${ }^{8}$ See Rubin et al. (14).

"This cell line is from an individual who is asymptomatic and thus is similar to the one described by Drefyus et al. (1975) (15). It was kindly provided by $D$. Poiteras. A full clinical report will be published elsewhere.

'Poiteras, D., M. H. Klavins, and D. J. Mahuran, unpublished data.

second allele has been characterized at the molecular level and shown to result in the insertion of eight amino acid residues in the carboxy terminus due to preferential splicing at the mutation site in intron 12 (19). They also argued that normal splicing could not occur in $>5 \%$ of $H E X B$ mRNAs (19). It is tempting to speculate, therefore, that the $3 \%$ residual Hex A activity observed in the patient's fibroblast (10) is due to $\beta$-subunits produced from low level $(<5 \%)$ of normally spliced mRNA. This argument is supported by the observation that the majority of the mutant polypeptide with the eight-amino acid insertion cannot fold properly and does not exit the endoplasmic reticulum (37). The ameliorating effect of the second allele must be even more dramatic in the adult and asymptomatic individuals who have one copy of the deletion allele. Therefore, the delineation of alleles in the homozygotes or coupled with null alleles can provide the means whereby the allele-specific manifestations of disease can be defined.

\section{Acknowledgments}

We would like to thank D. Poiteras of the Department of Gastroenterology, Hospital St. Luc, Montreal, Quebec, Canada for providing the cell line 2557. 


\section{References}

1. Sandhoff, K., E. Conzelmann, E. F. Neufeld, M. M. Kaback, and K. Suzuki. 1989. The $\mathrm{G}_{\mathrm{M} 2}$ gangliosidosis. In The Metabolic Basis of Inherited Disease. C. R. Scriver, A. L. Beaudet, W. S. Sly, and D. Valle editors. McGraw-Hill Book Co., New York. 1807-1842.

2. Mahuran, D., A. Novak, and J. A. Lowden. 1985. The lysosomal hexosaminidase isozymes. Isozymes. Curr. Top. Biol. Med. Res. 12:229-288.

3. Bearpark, T. M., and J. L. Stirling. 1978. A difference in the specificities of human liver $\mathrm{N}$-acetyl-beta-hexosaminidase $\mathrm{A}$ and $\mathrm{B}$ detected by their activities towards glycosaminoglycan oligosaccharides. Biochem. J. 173:997-1000.

4. Kytzia, H.-J., and K. Sandhoff. 1985. Evidence for two different active sites on human $\beta$-hexosaminidase A. J. Biol. Chem. 260:75687572.

5. Boedecker, H. J., W. J. Mellman, T. A. Tedesco, and C. M. Croce. 1975. Assignment of the human hex B to chromosome 5. Exp. Cell Res. 93:468.

6. Chern, C. J., R. Kenneth, E. Engel, W. J. Mellman, and C. M. Croch. 1977. Assignment of the structural genes for the $\alpha$ subunit of Hexosaminidase A, mannose phosphate isomerase and pyruvate kinase to the region of 22 qter of human chromosome 15. Somat. Cell Genet. 3:533-560.

7. Okada, S., and J. S. O'Brien. 1969. Tay-Sachs disease: generalized absence of a $\beta$-D-N-acetylhexosaminidase component. Science (Wash. DC). 165:698-700.

8. Sandhoff, K., U. Andreae and H. Jatzkewitz. 1968. Deficient Hexosaminidase activity in an exceptional case of Tay-Sachs disease with additional storage of kidney globoside in visceral organs. Pathol. Eur. 3:278.

9. Conzelmann, E., and K. Sandhoff. 1978. AB variant of infantile $\mathbf{G}_{\mathrm{M2}}$ gangliosidosis: deficiency of a factor necessary for stimulation of hexosaminidase A-catalyzed degradation of ganglioside $\mathrm{G}_{\mathrm{M} 2}$ and glycolipid $\mathrm{G}_{\mathrm{A} 2}$. Proc. Natl. Acad. Sci. USA. 75:3979-3983.

10. O'Dowd, B. F., M. H. Klavins, H. F. Willard, R. Gravel, J. A. Lowden, and D. J. Mahuran. 1986. Molecular heterogeneity in the infantile and juvenile forms of Sandhoff disease (O-variant $\mathrm{G}_{\mathrm{M} 2}$ Gangliosidosis). J. Biol. Chem. 261:12680-12685.

11. Oonk, J. G. W., H. J. van der Helm, and J. J. Martin. 1979. Spinocerebellar degeneration: Hexosaminidase A and B deficiency in two adult sisters. Neurology. 29:380-384.

12. Barbeau, A., L. Plasse, T. Cloutier, S. Paris, and M. Roy. 1984 Lysosomal enzymes in ataxia: discovery of two new cases of late onset hexosaminidase A and B deficiency (adult Sandhoff disease) in French Canadians. Can. J. Neurol. Sci. 11:601-606.

13. Federico, A., G. Ciacci, I. D'Amore, R. Pallini, A. Palmeris, A. Rossi, N. Rizzuto and G. C. Guazzi. 1986. $\mathrm{G}_{\mathrm{M} 2}$ gangliosidosis with hexosaminidase $A$ and $B$ defect: report of a family with motor neuron disease-like phenotype. J. Inher. Metab. Dis. 9:307-310.

14. Rubin, M., G. Karpati, L. S. Wolfe, S. Carpenter, M. H. Klavins and D. J. Mahuran. 1988. Adult onset neuronopathy in the juvenile type of hexosaminidase A and B deficiency. J. Neurol. Sci. 87:103-119.

15. Dreyfus, J.-C., L. Peonaru, and L. Svennerhold. 1975. Absence of hexosaminidase A and B in a normal adult. N. Engl. J. Med. 292:61-63.

16. Lowden, J. A., E. J. Ives, D. L. Keene, A. L. Burton, M. A Skomorowski, and F. Howard. 1978. Carrier detection in Sandhoff disease. Am. J. Hum. Genet. 30:38-45.

17. Der Kaloustian, V. M., M. J. Khoury, R. Hallal, Z. H. Idriss, M. E. Deeb, N. W. Wakid, and F. S. Haddad. 1981. Sandhoff disease: prevalent form of infantile $\mathrm{G}_{\mathrm{M} 2}$ gangliosidosis in Lebanon. Am. $J$. Hum. Genet. 33:85-89.

18. Dodelson de Kremer, R., C. D. Boldini, A. P. Capra, I. M.
Levstein, N. Bainttein, P. K. Hidalgo, and H. Hliba. 1985. Sandhoff disease: 36 cases from Cordoba, Argentina. J. Inher. Metab. Dis. 8:46-46.

19. Nakano, T., and K. Suzuki. 1989. Genetic cause of a juvenile form of Sandhoff disease: abnormal splicing of $\beta$-hexosaminidase $\beta$ chain gene transcript due to a point mutation within intron 12. J. Biol. Chem. 264:5155-5158.

20. Willard, H. F., K. D. Smith, and J. Sutherland. 1983. Isolation and characterization of a major tandem repeat family from the human $\mathrm{X}$ chromosome. Nucleic Acids Res. 11:2017-2038.

21. Church, G. M., and W. Gilbert. 1984. Genomic sequencing. Proc. Natl. Acad. Sci. USA. 81:1991-1995.

22. Neote, K., B. Bapat, A. Dumbrille-Ross, C. Troxel, S. M. Schuster, D. J. Mahuran, and R. A. Gravel. 1988. Characterization of the human HEXB gene encoding lysosomal $\beta$-hexosaminidase. Genomics. 3:279-286.

23. Grossberger, D. 1987. Minipreps of DNA from bacteriophage lambda. Nucleic Acids Res. 15:6737.

24. Maniatis, T., E. F. Fritsch, and J. Sambrook. 1982. Molecular Cloning: A Laboratory Manual. Cold Spring Harbor Laboratory, Cold Spring Harbor, NY. 545 pp.

25. O'Dowd, B. F., K. Neote, D. L. G. Munre, R. A. Gravel, D. Mahuran, and H. F. Willard. 1987. PstI RLFP in human hexosaminidase (HEXB) gene on chromosome 5. Nucleic Acids Res. 15:31943194.

26. Rattazzi, M. C., J. A. Brown, R. G. Davidson, and T. B. Shows. 1976. Studies on complementation of $\beta$ hexosaminidase deficiency in human $\mathrm{G}_{\mathrm{M} 2}$ gangliosidosis. Am. J. Hum. Genet. 28:143-154.

27. Wood, S. 1978. Juvenile Sandhoff disease: complementation tests with Sandhoff and Tay-Sachs disease using polyethylene glycolinduced cell fusion. Hum. Genet. 41:325-329.

28. Tsui, F., D. J. Mahuran, J. A. Lowden, T. Mosmann, and R. A. Gravel. 1983. Characterization of polypeptides serologically and structurally related to hexosaminidase in cultured fibroblasts. J. Clin. Invest. 71:965-973.

29. Schmid, C. W., and W. R. Jelinek. 1982. The Alu family of dipersed repetitive sequences. Science (Wash. DC). 216:1065-1070.

30. Bikker, B., F. M. van den Berg, R. A. Wolterman, J. M. de Vijlder, and P. A. Bolhuis. 1989. Demonstration of a Sandhoff disease-associated autosomal 50 -kb deletion by field inversion gel electrophoresis. Hum Genet. 81:287-288.

31. Myerowitz, R., and F. C. Costigan. 1988. The major defect in Ashkenazi Jews with Tay-Sachs disease is an insertion in the gene for the $\alpha$-chain of $\beta$-hexosaminidase. J. Biol. Chem. 263:18587-18589.

32. Lehrman, M. A., D. W. Russell, J. L. Goldstein, and M. S. Brown. 1987. Alu-Alu recombination deletes splice acceptor sites and produces secreted low lipoprotein receptor in a subject with Familial Hypercholesterolemia. J. Biol. Chem. 262:3354-3361.

33. Hobbs, H. H., M. S. Browm, J. L. Goldstein, and D. W. Russell. 1986. Deletion of exon encoding cysteine-rich repeat of low density lipoprotein receptor alters its binding specificity in a subject with familial hypercholesterolemia. J. Biol. Chem. 261:13114-13120.

34. Ottolenghi, S., and B. Giglioni. 1982. The deletion in a type of $\delta$ - $\beta$-thalassaemia begins in an inverted AluI repeat. Nature (Lond.). 300:770-771.

35. Jagadeeawaran, P., D. Tuan, B. G. Forget, and S. M. Weissman. 1982. A gene deletion ending at the midpoint of a repetitive DNA sequence in one form of hereditary persistence of fetal haemoglobin. Nature (Lond.). 296:469-470.

36. Huang, L.-S., M. E. Ripps, S. H. Korman, R. J. Deckelbaum, and J. L. Breslow. 1898. Hypobetalipoproteinemia due to an Apolipoprotein B gene exon 21 deletion derived by Alu-Alu recombination. $J$. Biol. Chem. 264:11394-11400.

37. Dlott, B., D. Quon, A. d'Azzo, and E. F. Neufeld. 1989. Characterization of the hexosaminidase Paris variant of $\beta$-hexosaminidase. Am. J. Hum. Genet. 43:A5.(Abstr.) 